\title{
Effect of Processing Parameters on Scale Formation During Hot Steel Strip Rolling
}

\author{
Sergio de Oliveira Lima Júnior ${ }^{\mathrm{a}}$, Júlio Cezar Bellon a, Paulo Antônio de Souza Júnior ${ }^{\mathrm{b}, \mathrm{d}}$, \\ Fernando Gabriel da Silva Araújo ${ }^{\mathrm{c}}$, André Barros Cota ${ }^{\mathrm{c} *}$ \\ ${ }^{\mathrm{a}}$ ArcelorMittal Tubarão, Serra, Brazil \\ ${ }^{\mathrm{b}}$ Rede Temática em Engenharia de Materiais - REDEMAT \\ 'Physics Departament - REDEMAT, Federal University of Ouro Preto \\ ${ }^{\mathrm{d}}$ Tasmanian ICT Centre, CSIRO, Hobart 7000 TAS, Australia
}

Received: March 13, 2008; Revised: December 5, 2009

\begin{abstract}
The influence of processing parameters (slab thickness, water flow of interstand cooling and oil flow in roll gap lubrication system) on the thickness and composition of the tertiary scale formed during hot strip rolling, was studied in a low carbon steel in factory. The scale formed on the rolled surface was characterized by scanning electron microscopy and Mössbauer spectroscopy. It was observed that the combined effect of a greater rolling oil volume applied, larger bar thickness, and smaller amount of water flow during interstand cooling reduces the tertiary scale thickness. Besides, a smaller crack density in the samples is associated with greater rolling oil volume and smaller oxide scale thickness. The principal phase of the scale formed in hot-rolled steel strips is stoichiometric magnetite, without isomorphic substitutions.
\end{abstract}

Keywords: hot-rolled strips, tertiary scale, Mössbauer spectroscopy

\section{Introduction}

During hot strip processing, tertiary scale forms on the steel surface after descaling or between each mill stand, at temperatures below $1000{ }^{\circ} \mathrm{C}$. The frictional phenomena and thermal conductivity at the interface between the roll and the steel will affect the rolling process, by changing rolling forces, torques, power consumptions, temperature gradient near the steel surface, roll wear and surface quality and even the mechanical and other properties of the bulk materials ${ }^{1-4}$. On carbon steel, the tertiary scale formed at high temperatures usually consists of three iron oxide phases, the inner wüstite $(\mathrm{FeO})$, magnetite $\left(\mathrm{Fe}_{3} \mathrm{O}_{4}\right)$ and the outer layer hematite $\left(\alpha-\mathrm{Fe}_{2} \mathrm{O}_{3}\right)^{1-5}$. The thickness of these three phases will be different with the changes of oxidation conditions, steel compositions and surface finish ${ }^{3,6}$.

The formation of oxide scales on steel at high temperatures has been widely studied because of its importance during the hot processing of steel. These studies were usually limited to specific materials at fixed temperatures and constrained oxidation times in experimental simulations ${ }^{1-3,6}$. However, only a few works investigated the scales formed on steels in factory, and showed great difference compared to the laboratory results, not only in the thickness but also in the phases compositions and strip surface quality ${ }^{2,5,7}$.

It is essential to study the influence of processing parameters on oxide scales formation during the hot strip rolling, because the secondary and tertiary scales should be removed before subsequent processing, i.e., cold rolling the steel. Besides this, the thin hot rolled strips with good surface quality could potentially be applied to final products without further processing.

The purpose of this paper is to analyze the influence of processing parameters: slab thickness, water flow of interstand cooling and oil flow in roll gap lubrication system, on the formation of the tertiary scale during hot strip rolling of low-carbon steel in factory. The scale occurrence is discussed considering two aspects: thickness and composition.

\section{Experiments}

The material used in the experiments was low carbon steel, whose composition in weight percentage was: $0.0425 \mathrm{C}, 0.03 \mathrm{Si}, 0.025 \mathrm{P}$, $0.015 \mathrm{~S}, 0.025 \mathrm{Al}$, and $0.004 \mathrm{~N}$. The experimental rolling was made at the six stands (F1 to F6) ArcelorMittal Tubarão's hot strip mill. Three parameters for the process of hot strips rolling were chosen, in a $2^{3}$ factorial project: slab thickness, water flow of interstand cooling or ISC (top and bottom) between stands F1/F2 and F2/F3, and applied oil flow in roll gap lubrication system (work rolls F2 to F4). The values for each parameter are described in Table 1 . The final rolling temperature was approximately $850{ }^{\circ} \mathrm{C}$ and the coiling temperature was approximately $660{ }^{\circ} \mathrm{C}$. The rolled strips had the following final dimensions for the transversal section: a thickness of $1.54 \mathrm{~mm}$ and a width of $1000 \mathrm{~mm}$. The remaining parameters for the process were not modified: reheating temperature of $1210 \pm 20^{\circ} \mathrm{C}$, primary and secondary descaling, 3 passes during reversing roughing mill and coil box.

The produced coils were reprocessed at the finishing lines at ArcelorMittal Tubarão. This was done, however, without inducing strip hardening and preserving the characteristics of the scale formed during hot rolling. Samples $100 \times 100 \mathrm{~mm}$ were taken from half the total length of the coil under each condition. The samples were prepared for metallography, etched, and the thickness of the scales formed (surface A - top; surface B - bottom) was evaluated using a Leica S440i scanning electron microscope (SEM). 
Table 1. Values used for the parameters during the experimental rolling process.

\begin{tabular}{|c|c|c|}
\hline Parameter & Value utilized & Observation \\
\hline Th & $28 \mathrm{~mm}$ and $32 \mathrm{~mm}$ & Slab thickness at the entrance of the finishing mill. \\
\hline ISC & $\begin{array}{l}12 \%\left(38 \mathrm{~m}^{3} / \mathrm{h}\right) \text { and } \\
20 \%\left(67 \mathrm{~m}^{3} / \mathrm{h}\right)\end{array}$ & $\begin{array}{l}\text { Relative percentage of the total water flow system; variations only in interstand } \\
\text { cooling } 1 \text { and } 2 \text {, which were equivalent, respectively to stands F1/F2 and F2/F3. }\end{array}$ \\
\hline Oil & $\begin{array}{l}-30 \% \text { and }+30 \% \\
\mathrm{~F} 2=130 \text { and } 230 \mathrm{~mL} / \mathrm{min} \mathrm{F} 3=120 \text { and } \\
220 \mathrm{~mL} / \mathrm{min} \mathrm{F} 4=100 \text { and } 180 \mathrm{~mL} / \mathrm{min}\end{array}$ & $\begin{array}{l}\text { Parameter with a variation of } \pm 30 \% \text { of the oil flow only in stands F2, F3 } \\
\text { and F4 in relation to the usual values utilized; in the other stands (F1, F5 } \\
\text { and F6), the values were not modified. }\end{array}$ \\
\hline
\end{tabular}

Table 2. Room temperature Mössbauer parameters obtained by the least-square fitting.

\begin{tabular}{lccc}
\hline \multicolumn{1}{c}{ Site } & $\delta^{*}(\mathrm{~mm} / \mathrm{s})$ & $\Delta(\mathrm{mm} / \mathrm{s})$ & $\Gamma(\mathrm{mm} / \mathrm{s})$ \\
\hline A (magnetite) & 0.67 & 0.08 & 0.27 \\
$\mathrm{~B}$ (magnetite) & 0.40 & -0.03 & 0.27 \\
$\alpha-\mathrm{Fe}$ & 0.00 & 0.00 & 46 \\
$\mathrm{Fe}_{1-\mathrm{x}} \mathrm{O}$ & 0.94 & 0.74 & 0.34 \\
\hline
\end{tabular}

*isomeric displacement in relation to $\alpha$-Fe; errors for $\delta^{1}, \Delta^{2}$ and $\Gamma^{3}=0.02 \mathrm{~mm} / \mathrm{s}$; for $\mathrm{B}_{\mathrm{hf}}{ }^{4}=1 \mathrm{~T}$; and

${ }^{1}$ Isomer shift; ${ }^{2}$ quadrupole splitting; ${ }^{3}$ line width of average height; and ${ }^{4}$ hyperfine magnetic field.

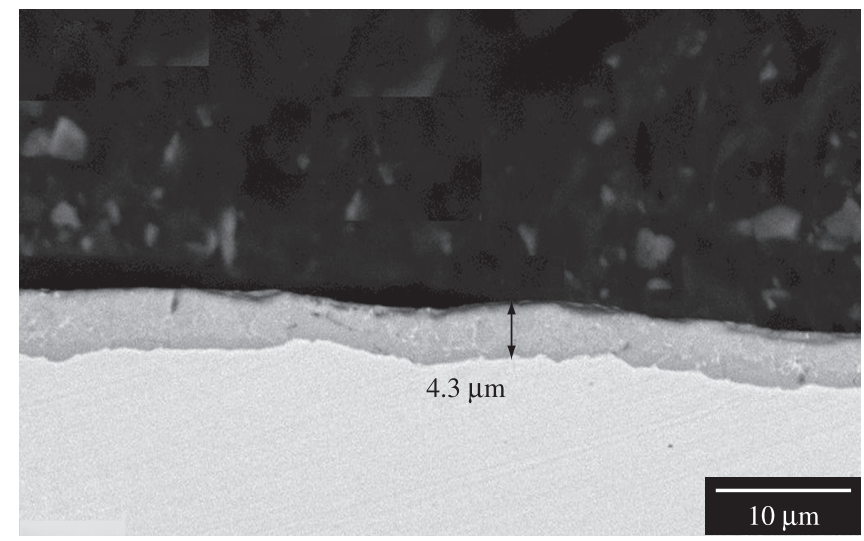

(a)

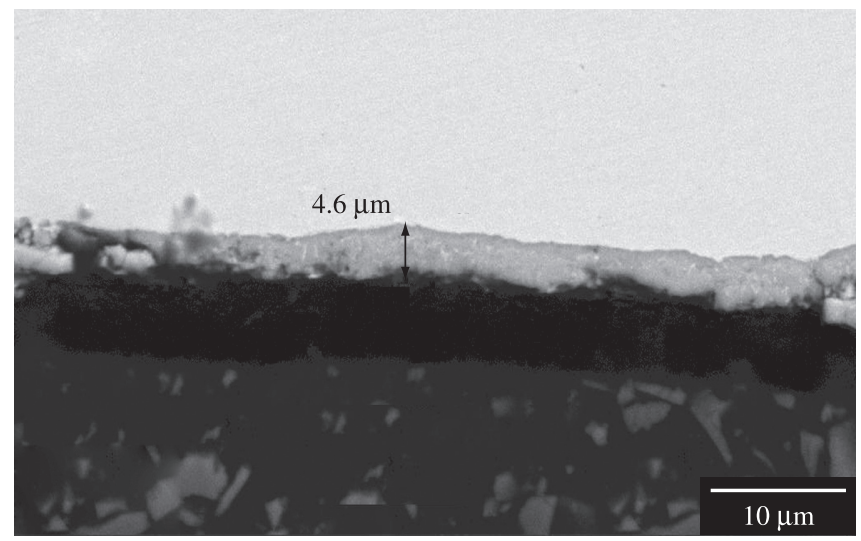

(b)

Figure 1. Image of a cross section of the A3 sample (ISC at $12 \%$; oil flow at $+30 \%$; slab thickness $=32 \mathrm{~mm}$ ) in SEM. a) surface top; and b) surface bottom.

The compositions of the oxide layers present in the scale were evaluated with the Mössbauer Spectrometer MIMOS II $^{8}$. This equipment performs experiments in backscatter geometry, using a source ${ }^{57} \mathrm{Co} / \mathrm{Rh}$ of $100 \mathrm{mCi}$ initial intensity. The spectra obtained were analyzed using a program for least-squares fitting to obtain the Mössbauer parameters $\left(\delta, \Delta, \mathrm{B}_{\mathrm{hf}}\right)$ and the spectral areas of each $\mathrm{Fe}$ site (Table 2).

\section{Results and Discussion}

The scale morphology was examined on both cross section and top views, using scanning electron microscopy. Figure 1 shows crosssection micrographs of the samples along the length of the strip. The micrographs show that the thickness of the tertiary oxide scale is relatively uniform and its value is practically the same in the two surfaces of each strip. The scale thickness varies from 3.8 to $7.7 \mu \mathrm{m}$, and these values agree with those published in the literature 9 .

Factorial analysis was used to evaluate the correlation of the processing parameters with the average values of the scale thickness formed in the two surfaces of each strip (Table 3). The results of factorial analysis are represented in Figure 2.

Figure 2 shows that the slab thickness, the ISC, and the oil parameters affected the thickness of the scale formed on the strip surface. The slab thickness has the greatest effect, as shown by the largest inclination of its straight line (Figure 2a). It can be observed that in general, the scale thickness decreases when using a slab thickness of $32 \mathrm{~mm}$, ISC at $12 \%$ and oil flow at $+30 \%$. This influence of the slab thickness on tertiary scale thickness through the factor time has been emphasized by Blazevic ${ }^{10}$.

The strip surface quality is associated to the scale thickness, which is characterized by defects, as cracks density, pores and blisters. Figure 3 shows a typical aspect in top view. A small crack density was observed in the samples that were rolled with flow oil at $+30 \%$ and with smaller tertiary scale thickness. The small crack density means that during the reduction pass the oxide undergoes the same percentage of reduction as the steel, due to plastic flow ${ }^{11}$. This is the desired situation, because it yields a flawless and relatively smooth strip with homogenous and compact scale. Bourdon et al. ${ }^{12}$ relate that a smaller oxide scale thickness implicates in a low pickling time.

According to Fagundes et al. ${ }^{13}$, the thinner the slab thickness, the smaller will be both its surface temperature and the difference in temperature between the nucleus and the surface. A smaller surface temperature reduces oxidation kinetics and, consequently, reduces fracture possibility in the oxidized layer during processing and also reduces the impression of this oxide on the metal base. Then, as this surface defect corresponds to the amount of oxide adhering to the strip surface, the thinner the slab thickness, the thinner the oxide layer and the better the surface quality of the strip surface. 
Table 3. Oxide Scale thickness and its respective processing parameters.

\begin{tabular}{ccccc}
\hline Sample & ISC $(\%)$ & Th $(\mathrm{mm})$ & Oil & Scale thickness $(\mu \mathrm{m})$ \\
\hline A1 & 12 & 28 & $+30 \%$ & 3.8 \\
A2 & 20 & & & 7.4 \\
A3 & 12 & 32 & & 4.5 \\
A4 & 20 & & & 5.0 \\
A5 & 12 & 28 & $-30 \%$ & 7.7 \\
A6 & 20 & & & 6.3 \\
A7 & 12 & 32 & & 4.6 \\
A8 & 20 & & & 5.1 \\
\hline
\end{tabular}

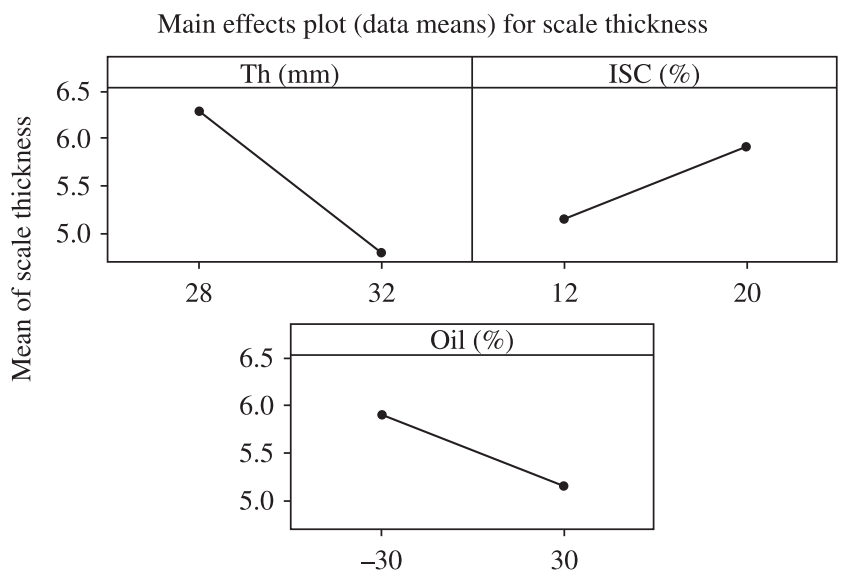

(a)

Interaction plot (data means) for scale thickness

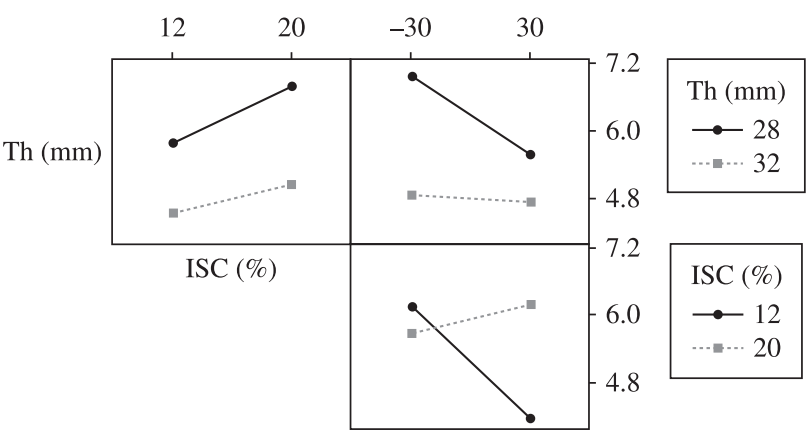

Oil (\%)

(b)

Figure 2. a) Effects of the processing parameters on the scale thickness; and b) effects of the interactions between the parameters on the scale thickness.

The composition of the scales present in the strips, in terms of the spectral area for the Fe sites detected, were the same for all the samples and the percentage values were: $\alpha-\mathrm{Fe}=63.44 ; \mathrm{Fe}_{3} \mathrm{O}_{4}$ ( site A-tetrahedral, $\mathrm{Fe}^{+3}$ ) $=22.5 ; \mathrm{Fe}_{3} \mathrm{O}_{4}$ (site B-octahedral, $\mathrm{Fe}^{+3}$ and $\left.\mathrm{Fe}^{+2}\right)=13.5$; and $\mathrm{Fe}_{1-\mathrm{x}} 0<1.0$. The depth of the backscatter analysis, using Mössbauer Spectrometer MIMOS II with radiation of $14.4 \mathrm{keV}$, reached and analyzed the steel substrate. The values presented in Table 2 represent the Mössbauer parameters obtained in the experiment, and the spectra of one of the samples is shown in Figure 4.

At room temperature, the spectra with two $\mathrm{Fe}$ sites in the stoichiometric magnetite are observed: site A (tetrahedral, $\mathrm{Fe}^{3+}$ ) and site $\mathrm{B}$ (octahedral, $\mathrm{Fe}^{3+}$ and $\mathrm{Fe}^{2+}$ ), at a ratio of 1:2, having an inverted spinel

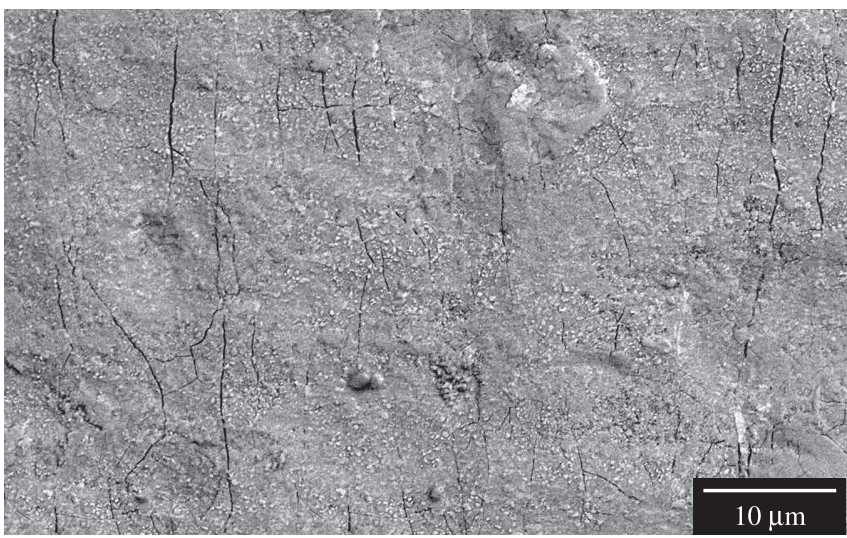

(a)

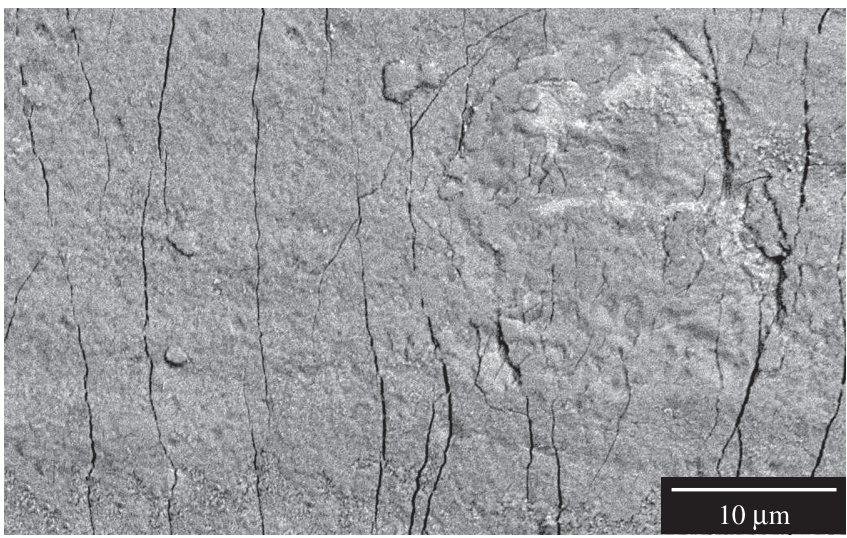

(b)

Figure 3. Image of top views of the a) A1 sample (ISC at 12\%; oil flow at $+30 \%$; slab thickness $=28 \mathrm{~mm}$ ); and b) A5 sample (ISC at $12 \%$; oil flow at $-30 \%$; slab thickness $=28 \mathrm{~mm}$ ) in SEM.

structure. Therefore, in this magnetite, the ratio of $\mathrm{Fe}^{3+} /\left(\mathrm{Fe}^{2+}+\mathrm{Fe}^{3+}\right)$ was calculated taking into consideration that the octahedral site had its iron atoms equally distributed between $\mathrm{Fe}^{2+}$ and $\mathrm{Fe}^{3+}$. This information was associated to the oxidation degree and purity of the magnetite. Purity, in this case, refers to the absence of isomorphic substitutions $\left(\mathrm{Fe}^{2+} \text { by } \mathrm{Mg}^{2+}, \mathrm{Ca}^{2+} \text { or } \mathrm{Ti}^{2+} \text { and } \mathrm{Fe}^{3+} \text { by } \mathrm{Al}^{3+}\right)^{14}$.

In the stoichiometric magnetite, given the considerations above, there is a ratio of $\mathrm{Fe}^{3+} /\left(\mathrm{Fe}^{2+}+\mathrm{Fe}^{3+}\right)=2 / 3=0.67$. An average of $0.69 \pm 0.02$ was obtained in the samples. As such, the magnetite found in the scale can be considered stoichiometric. This also signifies that isomorphic substitutions should not be expected in this magnetite.

The scale is $\mathrm{Fe}_{3} \mathrm{O}_{4}$ mixed with little $\mathrm{FeO}$, as a result of a common phenomenon for strips in which $\mathrm{FeO}$ will decompose into $\mathrm{Fe}_{3} \mathrm{O}_{4}$ and Fe via a eutectoid reaction, during the cooling of the steel coil, at temperatures below $570{ }^{\circ} \mathrm{C}$.

\section{Conclusions}

In this paper, the influence of processing parameters (slab thickness, water flow of interstand cooling and oil flow in roll gap lubrication system) on the characteristics of the tertiary scale formed during hot strip rolling of low-carbon steel in factory was analyzed.

It was observed that the combined effect of a greater rolling oil volume when compared to the usual industrial practice $(+30 \%$ : $\mathrm{F} 2 \rightarrow 230 \mathrm{~mL} / \mathrm{min}, \mathrm{F} 3 \rightarrow 220 \mathrm{~mL} / \mathrm{min}$ and F4 $\rightarrow 180 \mathrm{~mL} / \mathrm{min}$ ), larger slab thickness $(32 \mathrm{~mm})$ and smaller amount water flow of interstand cooling $\left(38 \mathrm{~m}^{3} \cdot \mathrm{h}^{-1}\right)$, reduces the tertiary scale thickness. Besides, a 


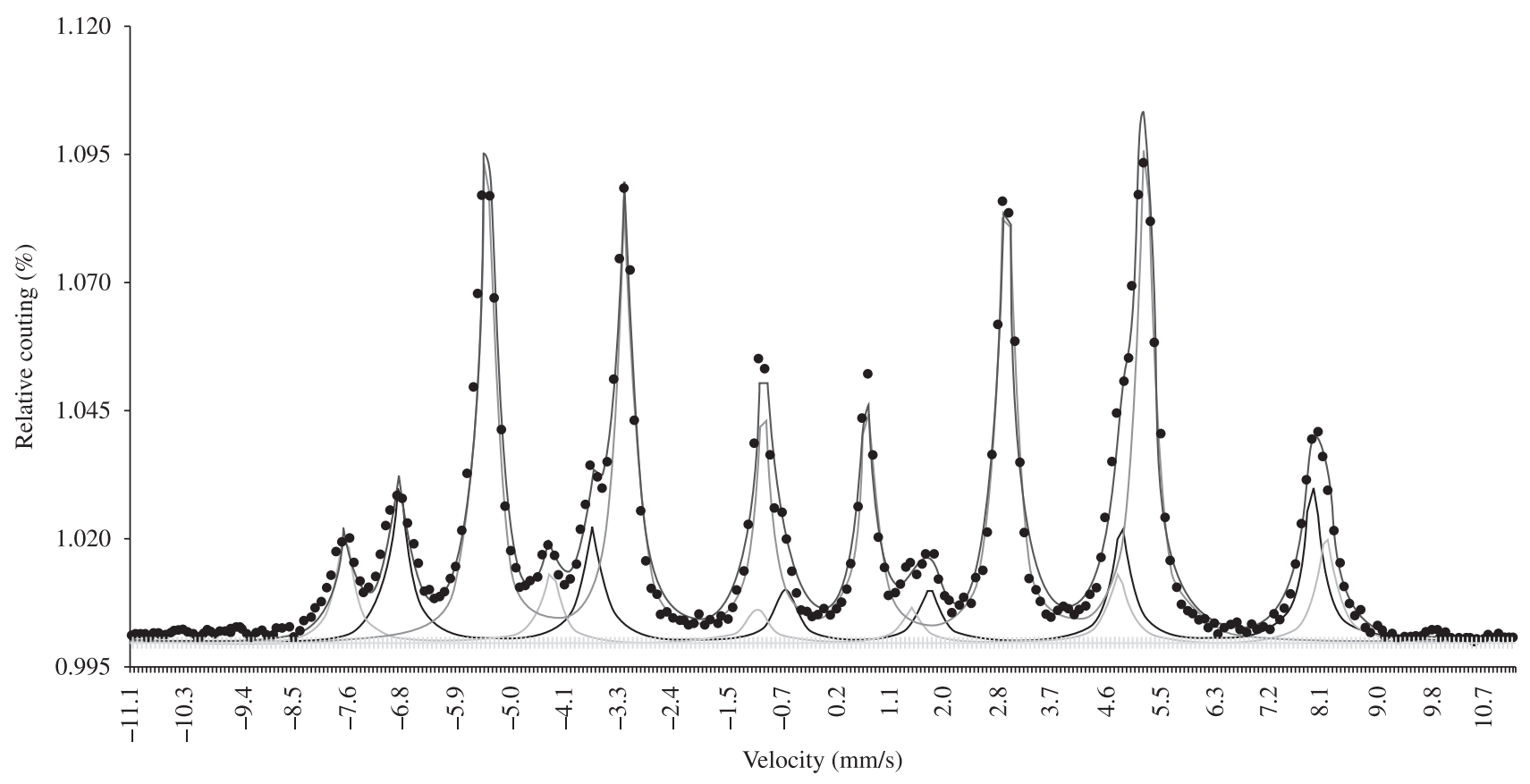

- Experimental data — Adjust $\quad$ Metallic iron $\quad$ Magnetite - A $\quad$ Magnetite - B $\quad$ Wüstite

Figure 4. Obtained Mössbauer MIMOS II4 spectra adjusted by the least square method (sample A2: ISC at $20 \%$; oil flow at $+30 \%$; slab thickness $=28 \mathrm{~mm}$ ).

smaller crack density in the samples that were rolled with flow oil at $+30 \%$ and with smaller oxide scale thickness was observed.

The principal phase of the scale formed in hot-rolled of steel strips is stoichiometric magnetite, without isomorphic substitutions.

\section{Acknowledgements}

The authors are grateful to ArcelorMittal Tubarão and REDEMAT/UFOP

\section{References}

1. Jiang ZY, Tieu AK, Sun WH, Tang JN and Wei DB. Characterization of Thin Oxide Scale and Its Surface Roughness in Hot Metal Rolling. Materials Science and Engineering A. 2006; 435-436:434-438.

2. Zhang $\mathrm{M}$ and Shao G. Characterization and Properties of Oxide Scales on Hot-Rolled Strips. Materials Science and Engineering A. 2007; 452-453:189-193

3. Sun W, Tieu AK, Jiang Z, Lu C and Zhu H. Surface Characteristics of Oxide Scale in Hot Strip Rolling. Journal of Materials Processing Technology. 2003; 140:76-83.

4. Torres M and Colás R. A Model for Heat Conduction through the Oxide Layer of Steel During Hot Rolling. Journal of Materials Processing Technology. 2000; 105:258-263.

5. Basabe VV and Szpunar JA. Grouth Rate and Phase Composition of Oxide Scales During Hot Rolling at Low Carbon Steel. ISIJ International. 2004; 44(9):1554-1559.

6. Sun W, Tieu AK, Jiang Z, Zhu H and Lu C. Oxide scales growth of low-carbon steel at high temperatures. Journal of Materials Processing Technology. 2004; 155-156:1300-1306.
7. Li CS, Xu JZ, He XM, Liu XH and Wang GD. Formation and Control of Strip Scale Pores in Hot Rolling. Journal of Materials Processing Technology. 2001; 116:201-204.

8. Klingelhöfer G, Morris RV, Bernhardt B, Radionov D and Souza Jr. PA, Squyres SW et al. Athena MIMOS II Mössbauer Spectrometer Investigation. Journal of Geophysical Research. 2003; 108(E12):8067.

9. Gines MJL, Benitez GJ, Perez T, Merli E, Firpo MA and Egli W. Study of the Picklability of 1.8 MM Hot-Rolled Steel Strip in Hydrochloric Acid. Latin American Applied Research. 2002; 32:281-288.

10. Blazevic DT. Tertiary Rolled in Scale: The Hot Strip Mill Surface Problem of 1990's. In: 37 $7^{\text {th }}$ Mechanical Working and Steel Processing Conference, vol. 33; 1996; Hamilton, Canada. Warrendale: Iron \& Steel Society; 1996. p. 33-38.

11. Browne KM, Dryden J and Assefpour M. Modeling Scaling and Descaling in Hot Strip Mills. In: Recent advances in heat transfer and microstructure modeling for metal processing MD vol. 67; 1995 November 12-17; San Francisco, USA. New York: ASME; 1995. p. 187-197.

12. Bourdon G, Eyden XV and Zeimetz E. Control of Scale Properties During Hot Rolling. In: $24^{\text {es }}$ Journées Sidérurgiques Internationales - La Revue de Métallurgie ATS; 2003 décembre 10-11; Paris, França. Paris: ATS; 2003. p. 46-47.

13. Fagundes Jr. J. Surface Quality Improvement in CST's Hot Strip Mill. In: AISTech 2005 Proceedings; 2005 May 9-12; Charlote, North Carolina, USA. Pittsburgh: Association for Iron and Steel Technology (AIST); 2005.

14. Souza Jr. PA. Extraterrestrial and Terrestrial Outdoor Applications of the Mössbauer Spectroscopy [PhD Thesis]. Mainz: Johannes Gutenberg Universität; 2004. 